\title{
Revisitando W. Kilpatrick e seus contributos visionários para a pedagogia na
}

\author{
atualidade
}

\section{Revisiting W. Kilpatrick and his visionary contributions towards nowadays pedagogy}

\author{
Esperança Jales Ribeiro, Sara Alexandre Felizardo \\ Escola Superior de Educação, Instituto Politécnico de Viseu (ESE, IPV/CI\&DETS/FCT) - Portugal
}

\begin{abstract}
Resumen
William Kilpatrick (1871-1965), educador e filósofo americano, foi uma das figuras cimeiras do movimento progressista para a educação. Revisitando o seu contributo refletiremos sobre as implicações do seu trabalho para a compreensão do modo como se aprende e da forma como se perpetivam o educador e o educando nesse processo, deixando, assim, antever aqueles que são os pressupostos essenciais a uma abordagem dialógica da prática educativa na atualidade.

Palabras clave: Kilpatrick, projeto, pedagogia, abordagem dialógica
\end{abstract}

\begin{abstract}
William Kilpatrick (1871-1965), American educator and philosopher, was one of the leading figures of the progressive movement for education. In revisiting his contribution we will consider the implications of his work for the understanding of how we learn and how educator and pupil are perspective in this process, anticipating those that are the essential assumptions to a dialogic approach of the educational practice in the present.

Keywords: Kilpatrick, project, pedagogy, dialogic approach
\end{abstract}

O contributo de Kilpatrick veio a ser considerado, no final do século XX, como um dos trabalhos mais influentes na área da produção filosófica sobre o ensino, dando origem a inúmeras publicações. A sua ideia da introdução do Método de Projeto (1918) surgiu na sequência do movimento de educação progressista, associado ao pensamento de John Dewey (1859-1952) e defendeu o experimentalismo, bem como a preocupação em associar a educação a objetivos pragmáticos (Knoll, 1997). Compartilhou, assim, com Dewey o desejo de que o currículo da escola refletisse os interesses dos educandos e assumiu a preocupação de que as atividades de resolução de problemas constituissem o cerne do processo educacional. A perspetiva de Kilpatrick enfatiza as atividades com um propósito nas quais as crianças se envolvem, associando-as intimamente à noção de projeto. Defendeu, nesta sequência, dois requisitos essenciais para o assumir de uma rutura com a pedagogia transmissiva e para a efetivação de mudanças fundamentais nas práticas educativas; $i$ ) romper com os valores de suporte positivista da estabilidade do mundo dado como certo; ii) assumir uma nova atitude metodológica assente no método de projeto.
Continuamos na atualidade, tal como na época, a reconhecer a necessidade de alterar procedimentos pedagógicos que cortem definitivamente com quadros concetuais ultrapassados, nomeadamente em defesa da necessidade de educar para uma sociedade assente nos princípios da globalização, massificação e mudança.

Kilpatrick contribuiu para derrubar as perspetivas que entendiam o aprendiz como ignorante ou um depósito, assim como, a conceção de educador compreendido como ser superior e detentor exclusivo do saber. Rejeitou, ainda, a ideia de que o processo educativo deveria assentar na transferência de conhecimento e a escola constituir-se como um meio de preparar para o que se há-de passar fora dela. Evidenciou, desta forma, a total desadequação destas conceções para o processo de ensino-aprendizagem, no século $\mathrm{XX}$, valorizando uma alternativa pedagógica autonomizante e inovadora. Nesta comunicação exploraremos dois aspetos essenciais para o entendimento da transformação a operar na relação educativa assente nos contributos de Kilpatrick: i) a valorização do pensamento crítico do educador, com recurso à perceção de uma mudança paradigmática; ii) o assumir de uma nova atitude metodológica de cariz comunicacional. Estes pressupostos conduzem a uma epistemologia das práticas (praxiologia), associada a uma atitude crítica, que ajuda a compreender o Método de Projeto, mas que não se esgota nele, na medida em que o que está em causa, é uma visão sobre; i) o modo como se aprende e ii) a forma como se perpetiva o sujeito nesse processo, deixando, assim, antever aqueles que são os pressupostos essenciais a uma abordagem dialógica da prática educacional na atualidade (séc. XXI).

\section{Educar para o desconhecido}

Uma vez que a dúvida está tão amplamente divulgada, pelo mundo, é lógico admitir que a mocidade duvide. $\mathrm{O}$ velho sistema caiu por terra. Não convém mais à mudança da civilização em que nos encontramos. Precisamos de um novo processo que prepare para o futuro desconhecido (Kilpatrick, 1965, p.59).

$\mathrm{Na}$ sua obra Educação para uma civilização em mudança (edição original 1926, nossa edição 1965), 
Kilpatrick referia-se a novas exigências para a educação resultantes de um fator que considerava essencial à época: a mudança civilizacional a que dizia assistir. Nesse sentido questionava-se sobre o que é que a mudança social reclamava à educação. Como resposta considerava a existência de duas tendências muito fortes com exigências de longo alcance: $i$ ) o declínio do autoritarismo e $i$ i) sentimento cada vez mais generalizado de que as coisas mudam quer queiramos quer não.

Tais afirmações poderiam ter sido feitas nos dias de hoje, mantendo a sua pertinência, tendo o pedagogo afirmado que a proporção da mudança tenderia a tornarse ainda mais célere, o que, por sua vez, exigiria que as próprias teorias básicas da Educação fossem reformadas. Nesta sequência, como resposta a este desafio, importaria levar as crianças a pensarem por si próprias, devendo as convicções dos educadores estarem capazes de resistir a essa prova. Tal afigurava-se-lhe difícil dado assumir que a sua geração não estava habituada a basear a sua conduta em nada "mais real que a tradição" (Kilpatrick, 1965, p. 33)

Kilpatrick (1965, p. 45) a propósito do avanço da ciência e transformações do mundo social afirmava: "tiramos a tampa do universo, desapareceu a nossa pretensão de impormos conclusões aos nossos filhos. Precisamos libertá-los para que pensem por si mesmos". Foi neste sentido que valorizou a abertura das escolas à exigências da democracia e da ética, continuando a defender que uma "geração não pode mais impor à seguinte as soluções que encontrou para os seus problemas" (Kilpatrick, 1965, p. 61).

Ken Robinson (2006), na sua conferência Do schools kill creativity?, defendeu exatamente esta ideia de que não conseguiremos hoje prever o que será a sociedade em 2065, quando os jovens que terminarem a sua escolaridade estiverem preparados para aceder ao mundo do trabalho. Questionou também este investigador sobre: Como prepará-los então para o futuro? O que valorizar do ponto de vista da sua formação? A sua resposta assentou na valorização da criatividade, como forma de gerir o desconhecido, assim como em competências a promover nas disciplinas de expressões e artes, tão importantes na formação quanto as de língua materna e matemática.

Kilpatrick entendia, na época, que poderíamos sempre "especialmente oferecer-lhes um inteligente controlo dos nossos melhores métodos de ação incluindo o de criticar esses métodos" (1965, p. 61) prevendo, desse modo, que não se anulasse a criatividade dos mesmos, estabelecendo diretivas: i) praticar o que queremos aprender: tal deveria acontecer de modo a que o professor criasse disposições favoráveis para a cooperação pois se desejamos que os alunos adquiram "o sentido de responsabilidade então precisam praticar a responsabilidade" (Kilpatrick, 1965, p.70); ii) experienciar o real, na escola: seria fundamental haver vida real na instituição escolar. Não se trata de adaptar a escola à vida mas de viver a vida em contexto escolar. Sem isso não se ofereceriam condições completas de aprendizagem, sendo que o mais alto sentido da experiência seria exatamente aquele em que o aprendiz contribuísse efetivamente com a sua iniciativa criadora, devendo a experiência ter um caráter social. Para o efeito, defendia que a escola deveria tornar-se mais democrática promovendo o autocontrolo dos alunos e uma nova moral capaz de suportar a prova da mudança assente no "porquê". A democracia, no sentido em que a caracterizou, exigiria assim o respeito pelos educandos e a disposição para cooperar no bem comum. A defesa de uma nova forma de entender a escola e os processos de aprendizagem assenta, na referida obra, nas mudanças civilizacionais previstas como constantes e exponenciais no futuro. Essas transformações implicariam por sua vez outra forma de conceber os processos, os educadores e os educandos. Estes últimos concebidos como ativos e competentes, pois dizia,"é preciso confiar nos alunos (...) confiar nas crianças em termos justos, é o único caminho da educação" (Kilpatrick, 1965, p. 88). Tratavase a este propósito, com o objetivo de promover o desenvolvimento dos educandos, de lhes permitir o prazer da pesquisa e a responsabilidade da escolha características valorizadas no método de projeto. Compreende-se assim a sua afirmação:

$\mathrm{Na}$ conceção antiga, a infância era (...) usada como preparação para a vida futura do adulto. Em consequência dava-se-lhe tudo aquilo que viessem a precisar mais tarde. Começamos agora a ver a futilidade de tal concepção. Não é como um celeiro ou frigorífico que a infancia pode ser eficientemente utilizada (Kilpatrick, 1965, p. 83).

A diferença de substância nas práticas só poderia efetivamente ser conseguida, segundo o autor, com uma atitude pedagógica que ajudasse a lidar com a mudança e preparasse para a incerteza do futuro. Dessa forma responder-se-ia na educação às exigências do mundo. Como? Usando de um pensamento crítico sobre a realidade rompendo com soluções dualistas.

\section{Pensamento crítico e necessidade de superação de soluções dualistas}

O pensamento crítico evidencia-se na obra de Kilpatrick (nossa edição, 1965), quando defende que é necessário reconhecer a mudança proporcionada pelo avanço da ciência, como uma constante:

No tocante a invenções notáveis, o último século tem mais a seu favor que milhares de anos anteriores (...) Declinará o grau da mudança? (...) o acervo, cada vez maior, desse pensamento, significará descobertas cada vez mais numerosas no domínio científico, pois as invenções dão-se numa progressão geométrica do aumento dos conhecimentos (...) se a curiosidade não diminuir, tornarse-á cada vez mais rápida a proporção da mudança (Kilpatrick, 1965, p. 35).

Essas mudanças apontavam para a industrialização, para a democracia e para uma nova atitude diante da vida que, segundo o autor (1965), resultavam da influência do pensamento baseado na experimentação, ou de modo geral no desenvolvimento da ciência. Haveria assim uma dificuldade em controlar e antever os resultados das mudanças e, portanto, a impossibilidade de educar para a previsibilidade. Afirmando que uma vez tirada a "tampa do universo" desaparecia a nossa pretensão de impor conclusões aos nossos filhos (Kilpatrick, 1965, p. 45). 
Nesta sequência, acabar com a moral social autoritária instituída (ausência de questionamento na justificação dos comportamentos) implicaria recusar que, em nome da tradição, se impusessem dogmas.

Se cada "vez menos os jovens aceitam como obrigatórias as convenções em vigor" e insistem nos porquês? E os resultados "não são assim tão maus" será que não poderão conduzir-nos a um "verdadeiro progresso em moral?" (Kilpatrick, 1965, p. 58).

Tratava-se de reconhecer que a experimentação no pensamento social e moral havia demonstrado que era necessário quebrar a autoridade, como era concebida e assumir um hábito que começava a generalizar-se, o de indagar dos porquês. Seria, pois, necessário apelar ao direito de duvidar e à capacidade de fundamentar as opções dando esse direito às crianças.

Nessa defesa o autor afirmava ser fundamental :

(...) preparar a nova geração acreditando que ela pode e deve pensar por si mesma ainda que a respeito, a respeito de certos pontos, seja seja para corrigir e rejeitar as nossas próprias conclusões. Nossas mais caras convicções têm que resistir a essa prova (Kilpatrick, 1965, p. 45).

Hoje sabemos que os avanços da ciência consagram as suas previsões e que estamos numa sociedade marcada pela velocidade vertiginosa de inovações, ritmos de vida e de trocas de informação. Vivemos cada vez mais uma cultura da instantaneidade e do direto, reduzindo-se drasticamente os períodos que medeiam entre o aparecimento de uma tecnologia e a sua inserção na sociedade. Estas mudanças que demandavam, já na altura, a necessidade de competências críticas, o aumento da capacidade de julgar, potenciavam a exigência da democracia e a necessidade dos educadores discutirem o significado das suas ações e decisões educacionais (a respeito do currículo e da escola), questionando os valores e procurando os mais adequados no sentido de tomarem decisões educacionais (políticas educacionais e específicas das escolas). Os professores não deveriam assumir uma posição neutra uma vez que as decisões que tomam, dentro da sala ou fora, seriam sempre apoiadas por convicções e pressupostos normativos.

Está em causa um empreendimento social e político que requer o nosso pensar mais profundo, abrangente e claro. Importaria, assim, que os mesmos se questionassem sobre:

Que tipo de visão social os agentes envolvidos no processo ensino-aprendizagem tendem a sustentar? Que tipo de vida social é suposto que apoiem ou devam apoiar? Que tipo de procedimentos ao nível da gestão da escola e do processo ensino-aprendizagem devem adoptar de forma a manter o padrão social desejado? (Kilpatrick, 1951, cit. Beyer, 1997, p. 476)

Tratava-se de interpretar metas e fins definidos por outras entidades e refletir e analisar as implicações éticas orais das suas ações. Os professores deveriam pois ser uma espécie de filósofos a ter que tomarem decisões.

Esta nova postura rejeita dicotomias inerentes ao paradigma positivista quando se recusa, por sua vez, a aceitar as mesmas, propondo alternativas. No caso, para a suparação da dualidade escola versus vida, a solução seria viver a vida verdadeira, a experiência real, na escola. A mensagem progressista consistente de Kilpatrick era a de que as escolas necessitavam de se (con)centrar mais na criança, serem mais democráticas e direcionadas para a sociedade. $\mathrm{O}$ mesmo argumentava que a melhor preparação para o futuro seria ajudar a criança a viver o presente, defendendo que para que os nossos alunos pudessem, por exemplo, adquir o sentido de responsabilidade precisariam de "praticar essa responsabilidade, com o desejo de serem bem sucedidos" (Kilpatrick, 1965, p.70).

Por sua vez, com o intuito de ultrapassar a dicotomia educando versus professor, a solução seria a realização do projeto como elemento unificador das aprendizagens na escola. $\mathrm{O}$ autor desvincula-se, deste modo, de formas padronizadas de mobilização de conhecimentos e propõe um elemento que associa professor e aluno num processo que exige a ambos, em relações recíprocas, criar ambientes favoráveis, encontrar caminhos de forma voluntária.Tal exigiria que o professor não ficasse cristalizado nos saberes, nos conteúdos ou matérias (até porque este acervo iria crescer exponencialmente) mas que se orientasse para o que era verdadeiramente importante os processos que permitiriam mobilizar os alunos, para as realizações (encontrar soluções), para o acesso fácil ao acervo.

Finalmente, atendendo ao último dualismo aquí abordado, método versus currículo, Kilpatrick propunha a transformação curricular, não segmentada no saber disciplinar, defendendo os saberes em função da vivência de situações problemáticas. Importa destacar que os resultados desta educação se identificam, assim, com o processo e não apenas com o produto, sendo que, a contínua reconstrução da experiência, consistiria na própria essência da educação, no sentido de maior capacidade em compreender, projetar, experimentar e conferir resultados. Este enfoque destaca a importância do processo de transformação da pessoa, do seu desenvolvimento. Contudo, é a relação interativa, dialética, democrática, entre pessoas e a sua realidade, bem como com o desenvolvimento de suas capacidades intelectuais e de sua consciência global que são por Kilpatrick valorizadas, "Qualquer aprendizagem deve visar a utilidade ao invés da lógica das matérias" (1965, p.79) defendendo que "É no desenvolvimento dos melhores meios que as matérias aparecem" (1965, p. 79). As questões colocadas pelo autor consistem, assim, numa "nova concepção curricular baseada na reconstrução contínua da experiência" (Paraskeva, 2007, p.7). Está em questão um currículo que, consistindo em experiências e utilizando matérias, não se reduz a estas, uma vez que, nesta perspetiva, andam juntos a criança, o currículo e a sociedade.

\section{Domínio de uma nova atitude: o método de projeto}

Ao inserir deliberadamente as aprendizagens escolares num contexto social Kilpatrick estava, portanto, a criar condições para a eficácia prática e para a responsabilidade moral, mas simultaneamente a arriscar na experiência do desconhecido.

O que Kilpatrick propôs foi a materialização de uma intenção (constante do ser humano) gerida, em conjunto, 
num processo de responsabilidades partilhadas. Segundo o mesmo, a ideia "unificadora encontrava-se numa actividade intencional feita com o coração, desenvolvendo-se num contexto social" (Kilpatrick, 2006, 320). Kilpatrick definiu, assim, o projeto como um acto intencional, voluntário, constituindo a "unidade típica da vida meritória numa sociedade democrática", pelo que, também deveria ser tornada a unidade típica do procedimento escolar" (Kilpatrick, 2007, p.15).

A expressão projeto, utilizada em pedagogia, remete para um meio a partir do qual os estudantes podem desenvolver um sentido de autonomia, independência e responsabilidade pondo em prática comportamentos sociais e de natureza democrática (Knoll, 1997). O termo 'projeto' surgiu então como um conceito que procurou unificar vários aspetos importantes relativos ao processo de aprendizagem: (i) a ação, e de preferência a ação realizada com empenho pessoal, (ii) a intencionalidade dessa ação, isto é, a existência de um objetivo, e (iii) a sua inserção num contexto social. Esta interpretação mais abrangente do termo "projeto" remete para o facto de este poder apresentar a variedade de propósitos atuais da vida (Waks, 1997).

A vivência de um projeto, aponta para uma relação entre necessidades e finalidades. Sendo que estas pressupõem liberdade de ação e o acesso a diferentes caminhos, para a sua realização, não podendo ser ditadas. Neste contexto, Kilpatrick estabeleceu que a motivação do aluno é a característica crucial da metodologia do projeto e está intimamente associada a aprendizagens significativas. Neste processo ficou valorizada a confiança na competência do aprendiz. Importa, ainda, situar que, por sua vez, o contexto social é, para o autor, também um espaço de avaliação, que exige a presença e a submissão ao contraditório, à apreciação dos pares e do próprio professor. Kilpatrick colocou, assim, tónica no fazer pela experiência, pela investigação, sujeitando à avaliação social, dos pares, os avanços nesse processo. A situação social é, desta forma, necessária para a avaliação comparativa de projetos. Kilpatrick asume, deste modo, um método que valoriza os alunos entendidos como autoregulados e competentes. Ao contrário de procurar um sistema para controlar e regular o comportamento do estudante esperou o melhor dos seus alunos, considerando-os pessoas reconhecidas nas suas realizações e respeitadas nos seus intereses, de forma a ampliar as suas experiências.

O compromisso aos valores e princípios democráticos tornou-se fundamental na orientação de Kilpatrick, como já referimos. Este assumiu que a democracia ultrapassa as ações relacionadas com um governo, estando relacionada com uma forma de vida com consequências morais e pessoais. As principais preocupações do educador deveriam passar pela responsabilidade em manter a individualidade do educando, ao mesmo tempo que visariam confinar o individualismo no processo ensino-aprendizagem.

\section{Síntese dos contributos de Kilpatrick na direção de uma abordagem dialógica da práxis}

De acordo com Knoll (1997), após a segunda guerra mundial, os críticos atacaram muitas das ideias e práticas dos partidários da instrução progressista. Viam no curriculum falta de rigor e estudantes academicamente impreparados para competir no âmbito de uma economia global. Críticas específicas, dirigidas a Kilpatrick, emergiram na literatura sobre a reforma escolar dos anos oitenta e noventa. Refere ainda Knoll (1997) que defensores do curriculum tradicional, encaravam a filosofia progressista que Kilpatrick tinha adoptado, como a causa principal para o declínio de padrões académicos que, na sua perspetiva, proliferava nas escolas americanas. Porém, durante o mesmo período, inúmeras pedagogias de orientação progressista foram implementadas nas salas de aula do país. As inovações incluíam a aprendizagem cooperativa, o ensino de equipa, a individualização da instrução, e os elementos experienciais do movimento da escola média/ secundária. Estas práticas, centradas no estudante, a par com o compromisso inabalável de Kilpatrick relativamente ao respeito pelos princípios democráticos nas escolas, constituem o núcleo do seu legado.

Kilpatrick rompeu com o paradigma da época por não se deixar influenciar pela narrativa vigente. Essa atitude, na medida em que tinha como referência o contexto da modernidade, e da industrialização massiva, de suporte positivista, levou-o a não se fixar neste, mas ao invés a usar de uma capacidade crítica, de desconstrução, assente numa narrativa que nega a perspetiva dos valores instituídos, dados como certos, em defesa de uma resposta unificadora (de elementos desfragmentados) e de uma atitude pluralista. Estas, por sua vez, parecem constituir, no presente, a resposta mais eficaz aos desafios do mundo contemporáneo (Garavan, 2013). É neste sentido que o contributo de Kilpatrick antevê o protagonizado pela abordagem dialógica em educação, na medida em que esta assenta numa visão comunicacional, com enfoque na subjetividade, surgindo como alternativa aos paradigmas ontológicos e positivistas (centrados na objetividade).

As teorias de diálogo têm as suas fontes num grande número de áreas, incluindo a filosofia, a psicologia, a antropologia e a neurociência. O que estas fontes têm em comum, é o reconhecimento de que a sociabilidade humana e a procura de sentido envolvem sujeitos em interação comunicativa uns com os outros. Inscritas num contexto designado de pós-moderno, estas correntes contemporâneas, entre as quais se destacam o construtivismo e o construcionismo social, procuram responder às exigências de um mundo efémero e em permanente mudança. Numa resposta crítica à modernidade, os autores aí integrados passaram a questionar a possibilidade da neutralidade dos investigadores na construção do conhecimento e, nessa sequência, de se conhecer objetivamente a realidade (Guanaes \& Mattos, 2011). De acordo com Gergen (1995), referenciado por Alves-Ferreira e Gonçalves (2001, p. 47), o tópico que mais acordo suscita entre as linhas de argumentação pós-moderna, constituindo um 
"marco de divisão mais claro entre o que é o moderno e o pós-moderno", é o "abandono da representação". Nesta ótica, o conhecimento não constitui a representação exata do mundo que a linguagem expressa, sendo que são os "significados retirados da cultura e da linguagem, que sustentam, encorajam ou reforçam certos processos ou interações sociais" (Alves-Ferreira \& Gonçalves, 2001, p. 47). A perspetiva pós-moderna carateriza-se, assim, pela ênfase dada à linguagem e à interação entre as pessoas na compreensão dos processos de construção de sentido (McNamee \& Gergen 1999), incentivando a procura de respostas às questões de saber i) como é que o processo interativo proporciona oportunidades para que surjam caraterizações particulares e ii) como é que contextos específicos proporcionam a emergência de discursos diferentes (Guanaes, 2006). Diferencia-se da perspetiva moderna, que, afirma a natureza essencial das coisas e visa revelar, por "procedimentos de observação controlada e cuidadosa, a estrutura básica ou a essência dos objetos investigados, a fim de tirar conclusões e estabelecer princípios" (Guanaes \& Mattos, 2011, p.109).

As perspetivas dialógicas sugerem que a compreensão envolve comunicação e esta, por sua vez, ocorre numa relação dinâmica. Por conseguinte, a comunicação não é uma troca de informações objetivas amarrada a uma intencionalidade prévia. Quando iniciamos uma participação num diálogo ajustamos o mesmo ao contexto, pelo que a intenção inicial, transforma-se, frequentemente, de acordo com o auditório (Morin, 1996). Segundo Bakhtin (1984, cit. Garavin, 2013, p.10), a vida, pela sua própria natureza, é dialógica, pelo que "viver significa participar nesse diálogo". Esta ênfase no pressuposto dialógico sustentou o trabalho de muitos investigadores onde se incluem Buber, Levinas, Habermas (Garavan, 2013), mas também Gergen, Bakhtin, Wittgenstein, Pearce e Shotter entre outros. Acima de tudo, é fundamental a compreensão de que a noção de diálogo abre a possibilidade de sair do mundo interno de cada indivíduo, sob a forma da relação interpessoal (Shotter, 2000). Trata-se de entender uma dimensão autoral dos sujeitos com que trabalhamos e perceber que a linguagem está ao serviço da emancipação da experiência e não do seu relato. Pressupõe a compreensão da realidade e dos sujeitos como estando em permanente mudança, valorizando-se a relação e o significado da linguagem, bem como a adjetivação da experiência e o papel ativo da mesma na construção de novas narrativas. Temos aqui, como nos diz Gonçalves (1997), uma deslocação concetual radical, com a passagem do "enfoque individualista" do conhecimento para um "enfoque dialógico", situado numa estrutura de intercâmbio, essencialmente inscrita na linguagem e na comunicação.

Kilpatrick, pelo modo como se posicionou na defesa de ideais que contrariavam o pensamente vigente na época, antecipou, de alguma maneira, a visão mais atual acerca dos protagonistas dos processos de ensinoaprendizagem. O seu contributo, foi, sem dúvida de natureza qualitativa encontrando-se sintetizado nas premissas a seguir identificadas: i) Apelo a uma postura crítica de questionamento, caracterizadora dos educandos e dos educadores, não outorgando as narrativas vigentes;

ii) Valorização de uma praxiologia sustentada na problematização;

iii) Rutura com o pensamento dualista;

iv) Incentivo a aprendizagens significativas no âmbito de processos comunicacionais;

v) Investimento nos processos de aprendizagem como ponto de partida para a mobilização de saberes;

vi) Valorização da subjetividade do aprendiz e da sua competência;

vii) Apelo ao trabalho colaborativo na valorização da construção partilhada do saber (respeito pelos princípios democráticos e ética);

viii) Valorização do social numa lógica argumentativa e avaliativa.

\section{Referências}

Alves-Ferreira, J. \& Gonçalves, O. (2001). Educação narrativa do professor. Coimbra: Quarteto.

Beyer, L. (1997). William Heard Kilpatrick (1871-1965). Perspectivas: revista trimestral de educación comparada, 28, 503-521.

Guanaes, C. (2006). A construção da mudança em terapia de grupo: um enfoque construcionista social. São Paulo: Vetor.

Guanaes, C. \& Mattos, A. (2011). Contribuições do movimento construcionista social para o trabalho com famílias na estratégia saúde da família. Saúde Sociedade, 20, 1005-1017. São Paulo.

Garavan, M. (2013). Dialogical practice in social work Towards a renewed humanistic method. Journal of Social Intervention: Theory and Practice, 22, 4-20. http://www.journalsi.org

Gonçalves, M. (1997). Psicoterapia e interioridade: da metáfora do auto-conhecimento à metáfora da criatividade. Psicologia: Teoria, Investigação $e$ Prática, 1, 265-274.

Kirkpatrick, J. (1997). The Project Method. In Marketing Education. In LeClair, \& Hartline (Ed.), Marketing Theory and Applications (pp. 8-12). Chicago, IL: American Marketing Association.

Kilpatrick, W. (1965). Educação para uma civilização em mudança (tradução da obra de 1926). S. Paulo: Edições Melhoramento.

Kilpatrick W. (2007). Método do Projecto (tradução do original 1918). Mangualde: Edições Pedago.

Knoll, M. (1997).The project method: its vocational education origin and international development. Journal of Industrial Teacher Education, 34,59-80.

Menezes, I. R. (2007). Método de projeto x projeto de trabalho: entre novas e velhas idéias, Sitientibus, 36, 109-125.

Morin, E. (1996). A noção de sujeito. In D. Scnitman (Org.). Novos paradigmas da subjetividade (pp. 4559). Porto Alegre: Artes Médicas.

Mcnamee, S. \& Gergen, K. (1999). Relational responsibility: resources for sustainable dialogue. Thousand Oaks: Sage Publications. 
Paraskeva, J. (2007). O currículo como reconstrução contínua da experiência. In W. Kilpatrick (2007), Método do Projecto (preámbulo à tradução do original) (pp.5-9). Mangualde: Edições Pedago.

Robinson, K. (2006). Do schools kill creativity? California: TEDtalks.

Shotter J. (2000) Inside dialogical realities: From an abstract- systematic to a participatory- wholistic understanding of communication. Southern Communication Journal, 65, 119-132. doi: 10.1080/10417940009373162

Waks, L. (1997). The Project method in postindustrial education. Curriculum Studies, 29, 391-406. 